\title{
A Journey Around the COVID-19 vaccine for Athletes
}

\author{
Rankin, A. ${ }^{1}$, McLarnon, M. ${ }^{2}$, Hull, J.H. ${ }^{3,4,5,6}$, Gomes, C. ${ }^{3}$ and Heron, N. ${ }^{1,2,7}$ \\ 1. Sport Institute Northern Ireland, Belfast, UK \\ 2. Centre for Public Health, Queen's University Belfast, UK \\ 3. English Institute of Sport, London, UK \\ 4. Department of Respiratory Medicine, Royal Brompton Hospital, London, UK \\ 5. UK Sport, London \\ 6. Institute of Sport, Exercise and Health, University College London, UK \\ 7. Department of General Practice, Keele University, UK
}

* Correspondence: (N.H.) N.Heron@qub.ac.uk.

Received: 4 May 2021; Accepted: 30 June 2021; Published: 30 June 2021

Keywords: Athlete; COVID-19; vaccine; vaccination; sport

\section{Introduction}

This infographic outlines considerations for athletes and their teams around vaccination against the SARS-CoV-2 (Covid19) virus. There are currently three vaccines approved for use in the United Kingdom (UK); Pfizer/BioNTech, Moderna and Oxford/AstraZenica.

It is important for athletes and their physicians to be aware of the potential side effects from any given COVID-19 vaccination, pros and cons of vaccination in a low-risk population, and the logistics of training around vaccination administration. Finally, education surrounding vaccination may help combat vaccine hesitancy in an athletic population.

\section{Available vaccines}

In the UK, so far, the Pfizer/BioNTech and Oxford/AstraZenica vaccines have been made available to healthcare workers and 'vulnerable' patient groups, respectively, although the AstraZenica vaccine is now restricted to those 30 years of age or older.(1) Several million doses of the more recently approved Moderna vaccine have been ordered. Other vaccines have been approved for use elsewhere in the world, and further vaccinations may be approved within the UK.(2)

Pfizer and Moderna are both novel mRNA-based vaccines,(2) requiring two doses each, ideally 3-4 weeks apart (currently 12 weeks apart),(1) to achieve maximum efficacy. One dose is sufficient to prevent severe COVID-19 in $88.9 \%$ and $100 \%$ of patients, respectively, with both achieving immunity in just over $94 \%$ subjects after second dose.(2) The desired immune response may not be achieved for one to two weeks following vaccination.

The AstraZenica/Oxford vaccine is a chimpanzee adenovirus vector vaccine.(2) Also requiring two doses, one dose has been shown to prevent severe COVID-19 infection in $100 \%$ subjects after 28 days, but following two doses, a lower overall immunity is achieved of $70.4 \%$ at two weeks post vaccination.(2) Efficacy may be lower upon exposure to novel SARS-CoV-2 variants.(2) Therefore athletes travelling to countries with non-UK novel variants in circulation, should perhaps consider one of the other available vaccines.

Vaccines should not be mixed (i.e., if an athlete receives a first dose of one vaccine their second dose must be of the same vaccine). The vaccine should be administered to the athlete's non-dominant arm. 


\section{Side effect profile}

Both the Pfizer/BioNTech and Oxford/AstraZeneca vaccines have similar side effect profiles.(3-5) Common side effects include local discomfort surrounding the injection site, tiredness, headache, and flulike symptoms. $(3,5)$ Side effects typically appear within 1-2 days and do not persist beyond a few days.(3) They tend to be more severe following the second vaccine dose.(3)

\section{Pros and cons of vaccination}

In a generally low risk group, the benefits and potential harms of vaccination must be given greater consideration and discussed openly with the athlete.

There are several reasons athletes should take the vaccine. Elite athletes may be at increased risk of infection due to travel and may additionally require proof of vaccination to enter the host country. $(6,7)$ Moreover, although illness is often mild, there is still potential for "long-covid" (more common in younger populations) and cardiorespiratory sequelae.(8-10) There is additionally a risk of having to subsequently quarantine, if infected. All these factors may negatively impact an athlete's training. Vaccination also has the potential to prevent spread to family members or team-mates.

Athletes may refuse vaccination due to their low risk of serious illness and potential concerns around any of the vaccines and side effects, which should be openly discussed with the athlete and their representatives. Strenuous training is not recommended in the 24-48 hours after vaccination, and the timing surrounding both doses may impact the athletes' training schedule.(6) These factors aside, a significant minority of the population are generally "vaccinesceptic",(11) and the athlete may fall into this group.

\section{Logistics and other considerations for athletes.}

Prior to vaccination, athletes may train as normal. On the day of vaccination, they may train but should consider reducing exercise intensity. Athletes should ensure they are well and notify the vaccinator if they have previously experienced anaphylaxis,(4) or if they are pregnant.(12)

The day of vaccination should be considered around the athlete's training and competition schedule, as the previously mentioned short term side effects may hinder training.(6) Training may need to be reduced for several days following vaccination,(6) (e.g. for a 10 day period. Guidance should be sport-specific, as certain disciplines require greater arm involvement compared to others and are of different physiological intensities). Common side effects can be managed with simple analgesia and anti-pyretics, (e.g., paracetamol)(3). Athletes should be counselled on the two-week interim postinjection period before the vaccine becomes efficacious.

It should finally be impressed upon the athlete that vaccination does not provide $100 \%$ immunity, and therefore they must still adhere to government and local sporting guidance regarding preventative measures.

Contributorship: AR, JH and $\mathrm{NH}$ conceived the idea for the infographic; MMcL produced first drafts on the introduction for the infographic with supervision by $\mathrm{NH}$ and $\mathrm{AR}$ produced the first draft of the infographic; all authors then provided revisions to these documents and agreed the final drafts; all authors reviewed and edited several revisions of the manuscript, with all authors approving the final manuscript.

Supplementary Materials: The following are available online at www.jsc-cycling.com/xxx, Figure S1: title, Table S1: title, Video S1: title.

Funding: Please add: "This research received no external funding".

Conflicts of Interest: The authors declare no conflict of interest. 


\section{References}

1. UK COVID-19 vaccines delivery plan. In: Care DoHaS, editor. 2021.

2. Creech CB, Walker SC, Samuels RJ. SARSCoV-2 Vaccines. JAMA. 2021.

3. Prevention CfDCa. Possible Side Effects After Getting a COVID-19 Vaccine: National Center for Immunization and Respiratory Diseases (NCIRD), Division of Viral Diseases; 2021 [updated 10/03/21. Available from:

https://www.cdc.gov/coronavirus/2019ncov/vaccines/expect/after.html.

4. Prevention CfDCa. Information about the Pfizer-BioNTech COVID-19 Vaccine 2021 [updated 04/03/21. Available from: https://www.cdc.gov/coronavirus/2019ncov/vaccines/different-vaccines/PfizerBioNTech.html.

5. Agency MHpR. Information for Healthcare Professionals on COVID-19 Vaccine AstraZeneca gov.uk2021 [updated 22/02/21. Available from: https://www.gov.uk/government/publicatio ns/regulatory-approval-of-covid-19-vaccineastrazeneca/information-for-healthcareprofessionals-on-covid-19-vaccineastrazeneca.

6. Hull JH, Schwellnus MP, Pyne DB, Shah A. COVID-19 vaccination in athletes: ready, set, go... The Lancet Respiratory Medicine. 2021.

7. McLarnon M, Heron N. The COVID-19 athlete passport: a tool for managing athlete
COVID-19 status surrounding the Tokyo 2020 Olympic games. The Physician and Sportsmedicine. 2021:1-4.

8. Dores H, Cardim N. Return to play after COVID-19: a sport cardiologist's view. BMJ Publishing Group Ltd and British Association of Sport and Exercise Medicine; 2020.

9. Wilson MG, Hull JH, Rogers J, Pollock N, Dodd M, Haines J, et al. Cardiorespiratory considerations for return-to-play in elite athletes after COVID-19 infection: a practical guide for sport and exercise medicine physicians. British Journal of Sports Medicine. 2020;54(19):1157-61.

10. NIHR. Living with covid-19. A dynamic review of the evidence around ongoing covid-19 symptoms (often called long covid).2020. Available from: https://evidence.nihr.ac.uk/themedreview/li ving-with-covid19/.

11. Freeman D, Waite F, Rosebrock L, Petit A, Causier C, East A, et al. Coronavirus conspiracy beliefs, mistrust, and compliance with government guidelines in England. Psychological Medicine. 2020:1-13.

12. Agency MHpR. Information for UK recipients on COVID 19 Vaccine AstraZeneca: gov.uk; 2021 [Available from: https://www.gov.uk/government/publicatio ns/regulatory-approval-of-covid-19-vaccineastrazeneca/information-for-uk-recipientson-covid-19-vaccine-astrazeneca. 


\section{COVID-19 Vaccination \& Elite Sport}

\begin{tabular}{|c|c|c|c|c|c|}
\hline \multicolumn{2}{|c|}{ Current vaccinations available } & $\begin{array}{l}\text { Dosage \& recommended } \\
\text { interval (days) }\end{array}$ & & Overall efficacy $(\%)$ & Current approvals \\
\hline $\begin{array}{l}\text { Moderna (US) } \\
\text { mRNA-1273 }\end{array}$ & mRNA & 面 & $\begin{array}{l}\text { Dose 1: } \\
\text { Dose 2: }\end{array}$ & $\begin{array}{r}92.1 \% \\
94.1 \% \\
\end{array}$ & \\
\hline $\begin{array}{l}\text { Pfizer-BioNTech (US) } \\
\text { BNT162b2 }\end{array}$ & mRNA & 面 & $\begin{array}{l}\text { Dose 1: } \\
\text { Dose 2: }\end{array}$ & $52 \%$ & \\
\hline $\begin{array}{l}\text { AstraZeneca/Oxford (UK) } \\
\text { AZSI222 }\end{array}$ & Viral vector & 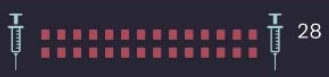 & $\begin{array}{l}\text { Dose 1: } \\
\text { Dose 2: }\end{array}$ & $\begin{array}{l}64.1 \% \\
70.4 \%\end{array}$ & \\
\hline $\begin{array}{l}\text { Gam-COVID-Vac (Russia) } \\
\text { Sputnik V }\end{array}$ & Viral vector & ${ }_{T}^{T}$ & $\begin{array}{l}\text { Dose 1: } \\
\text { Dose 2: }\end{array}$ & $\begin{array}{r}87.6 \% \\
91.1 \% \\
\end{array}$ & \\
\hline $\begin{array}{l}\text { Sinovac Biotech (China) } \\
\text { CoronaVac }\end{array}$ & $\begin{array}{l}\text { Inactivated } \\
\text { virus }\end{array}$ & $\underset{\text { 直 }}{\mathbf{T}}$ & Dose 2: & Up to $91.25 \%$ & \\
\hline $\begin{array}{l}\text { Sinopharm } 1 / 2 \text { (China) } \\
\text { BBIBP-CorV }\end{array}$ & $\begin{array}{l}\text { Inactivated } \\
\text { virus }\end{array}$ & 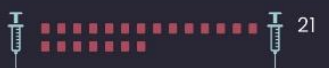 & Dose 2: & Up to $86 \%$ & \\
\hline
\end{tabular}

Side effect profile of current vaccinations

AstraZeneca* Injection site pain Fatigue ${ }^{*}$

\section{Considerations surrounding COVID vaccination}
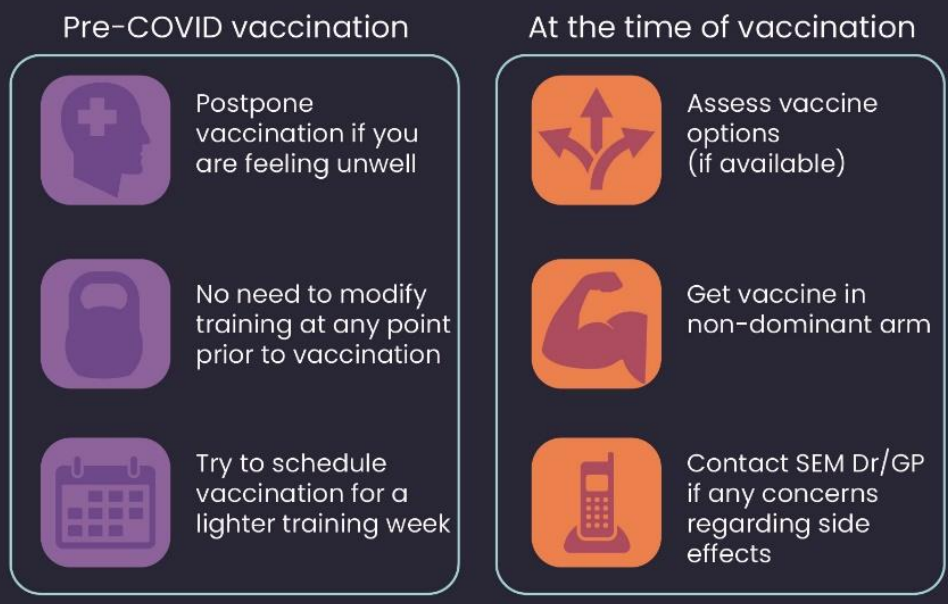

Post-COVID vaccination

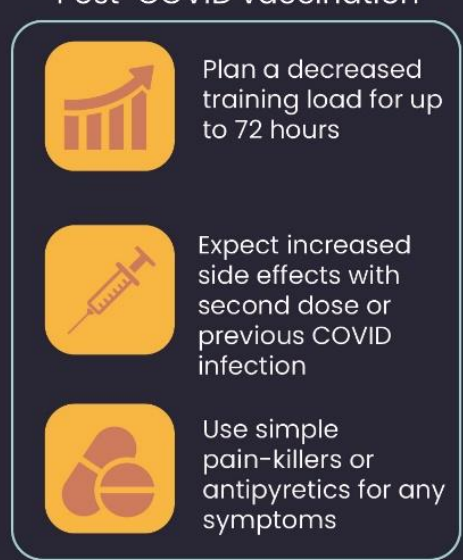

